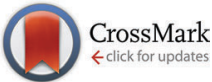

Cite this: Phys. Chem. Chem. Phys., 2016, 18, 4496

Received 30th September 2015 Accepted 4th January 2016

DOI: $10.1039 / c 5 c p 05850 c$

www.rsc.org/pccp

\title{
Chemical and physical processes in the retention of functional groups in plasma polymers studied by plasma phase mass spectroscopy $\dagger$
}

\author{
Joonas Ryssy, ${ }^{a}$ Eloni Prioste-Amaral, ${ }^{b}$ Daniela F. N. Assuncao, ${ }^{c}$ Nicholas Rogers, ${ }^{\text {de }}$ \\ Giles T. S. Kirby, ${ }^{\text {de }}$ Louise E. Smith ${ }^{\mathrm{ef}}$ and Andrew Michelmore ${ }^{\star \mathrm{ef}}$
}

\begin{abstract}
Surface engineering of functionalised polymer films is a rapidly expanding field of research with cross disciplinary implications and numerous applications. One method of generating functionalised polymer films is radio frequency induced plasma polymerisation which provides a substrate independent coating. However, there is currently limited understanding surrounding chemical interactions in the plasma phase and physical interactions at the plasma-surface interface, and their effect on functional group retention in the thin film. Here we investigate functionalised plasma polymer films generated from four precursors containing primary amines. Using XPS and fluorine tagging with 4-(trifluoromethyl)benzaldehyde, the primary amine content of plasma polymer films was measured as a function of applied power at constant precursor pressure. The results were then correlated with analysis of the plasma phase by mass spectrometry which showed loss of amine functionality for both neutral and ionic species. Surface interactions are also shown to decrease primary amine retention due to abstraction of hydrogen by high energy ion impacts. The stability of the plasma polymers in aqueous solution was also assessed and is shown to be precursor dependent. Increased understanding of the chemical and physical processes in the plasma phase and at the surface are therefore critical in designing improved plasma polymerisation processes.
\end{abstract}

\section{Introduction}

Surface engineering is growing as a field of research, and one that frequently crosses the disciplines of chemistry, physics and biology. ${ }^{1}$ Thin film coatings are added to surfaces as barrier coatings, or to impart specific properties such as hardness, roughness or wettability. ${ }^{2}$ Particularly in the area of micro and nanotechnology, the increase in surface to volume ratio as devices become ever smaller necessitates the ability to tailor surfaces with thin films $(<10 \mathrm{~nm})$ for a variety of applications. ${ }^{3}$

${ }^{a}$ School of Information Technology and Mathematical Sciences, University of South Australia, Mawson Lakes Campus, Mawson Lakes, SA, 5095, Australia

${ }^{b}$ Department of Industrial Engineering, Universidade Federal de Sao Carlos, Sorocaba Campus, Highway John Leme dos Santos, Sao Paulo, 18052-780, Brazil ${ }^{c}$ Department of Materials Engineering, Centro Federal de Educacao Tecnologica de Minas Gerais, 5253 Amazonas Avenue, Nova Suiça, 30480-000, Belo Horizonte, Brazil

${ }^{d}$ Future Industries Institute, University of South Australia, Mawson Lakes Campus, Mawson Lakes, SA, 5095, Australia

${ }^{e}$ Cooperative Research Centre for Cell Therapy Manufacturing,

University of South Australia, Adelaide, South Australia 5000, Australia.

E-mail: andrew.michelmore@unisa.edu.au

${ }^{f}$ School of Engineering, University of South Australia, Mawson Lakes Campus, Mawson Lakes, SA, 5095, Australia

$\dagger$ Electronic supplementary information (ESI) available. See DOI: 10.1039/c5cp05850c
Functionalised thin film surface coatings are used to improve biocompatibility, ${ }^{4}$ for biomolecule attachment, ${ }^{5}$ to fabricate antibacterial $^{6}$ and non-fouling surfaces ${ }^{7}$ and as grafting platforms. ${ }^{8}$ Specific applications include drug delivery, ${ }^{9}$ biosensors, ${ }^{10}$ membranes for fuel cells, ${ }^{11}$ and surfaces for cell attachment, proliferation and delivery. ${ }^{12}$ In some cases a balance between adhesion and release must be achieved, requiring that chemical functionality be precisely controlled. ${ }^{13}$

Techniques for functionalizing surfaces include self-assembled monolayers (SAMs), ${ }^{14}$ direct chemical grafting, ${ }^{15}$ physisorption ${ }^{16}$ and UV-induced polymerisation. ${ }^{17}$ Factors limiting industrial uptake of these techniques include that they are wet chemical processes requiring subsequent drying stages, and the requirement for specific substrate chemistry (e.g. thiol grafting to gold substrates). Plasma polymerisation offers the ability to rationally design surface density of functional groups via a single step, substrate independent and solvent free process. While this technique was first reported in $1960^{18}$ it was not until the 1980s when the ability to fabricate chemically functionalised surfaces was exploited. ${ }^{19}$ Through judicious choice of precursor and process parameters, surfaces can be fabricated with varying degree of functionality, but also degree of cross-linking in the plasma polymer bulk. The former determines their surface chemical properties such as surface potential and wettability, ${ }^{20}$ 
while the latter affects solubility and mechanical properties of the film. ${ }^{21}$

Recent studies have shown that understanding the physical processes of deposition from plasma can be used to simultaneously control functional group retention and cross-linking, enabling optimization of film properties. However, correlating process parameters (power input, gas flowrate etc.) with process outputs (film chemistry) is fraught as this misses the critical reactions that occur in the plasma phase, where energetic and reactive species are created which can deposit on surfaces. ${ }^{22}$ Therefore understanding the processes in the plasma phase ${ }^{23,24}$ and plasma-surface interactions $s^{25-27}$ is crucial. The plasma phase of organic plasmas quickly become very complex, with fragmentation and oligomerisation reactions occurring simultaneously. ${ }^{28}$ In principle, detailed understanding of these reactions should enable plasma polymer films to be tailored a priori. While this is not currently possible, detailed chemical and physical observation of the plasma is. Therefore, plasma phase mass spectrometry is a powerful, but under-utilized tool in the fabrication of functionalised plasma polymers.

Amine functionalised surfaces are useful for electrostatic/ covalent attachment of biomolecules, and have been demonstrated to improve cell adhesion. ${ }^{29}$ However, in general, primary amine group density increases film solubility in aqueous solution as they act as sites for water to hydrogen bond. The current study aims to elucidate the processes of functional group loss in plasma polymerisation for four commonly used amine containing precursors. Elemental and functional group surface analysis by XPS are correlated with plasma phase mass spectrometry. Analysis reveals the physical and chemical processes in the plasma phase and at the surface which lead to loss of amine functionality.

\section{Methods}

\section{Reagents}

Precursors 1,2-ethylenediamine (EDA), allylamine (AA), heptylamine (HA) and 1,3-diaminopropane (DAP) were purchased from Sigma Aldrich ( $>97 \%$ ) and used as received. Structures of the precursors are given in Fig. 1. 4-(Trifluoromethyl) benzaldehyde (TFBA) was also purchased from Sigma Aldrich and was stored under an Argon atmosphere to avoid reaction with nitrogen in the air. Glass coverslips were purchased from ProSciTech and were cleaned prior to use by rinsing in ethanol before drying under a stream of dry nitrogen.

\section{Plasma reactor and diagnostics}

A parallel plate reactor was used throughout, as previously characterized. ${ }^{30}$ The reactor consisted of a grounded $30 \mathrm{~cm}$ diameter steel cylinder with a height of $25 \mathrm{~cm}$. The electrode was an internal $28 \mathrm{~cm}$ diameter plate located approximately $1 \mathrm{~cm}$ below the top of the reactor. RF power at $13.56 \mathrm{MHz}$ was supplied to the top electrode via a Coaxial Power Systems (UK) generator (RFG050) with a matching network (AMN150). The chamber was evacuated using a rotary pump to a base pressure of below $1 \times 10^{-3}$ mbar. Precursor vapours were introduced to

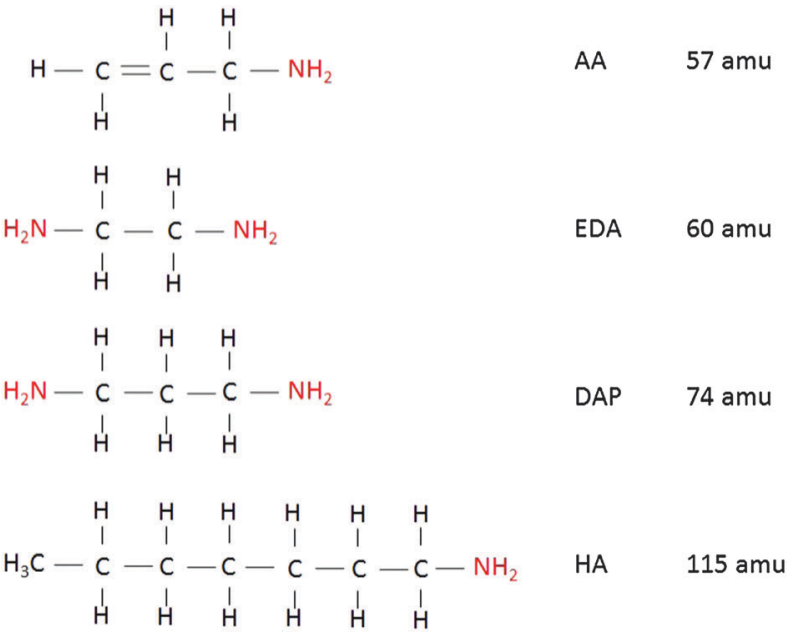

Fig. 1 Chemical structures of precursors used. Primary amine functional groups are highlighted in red.

the chamber via a needle valve (Chell, UK) after several freeze/ thaw cycles of the precursor to remove dissolved air. The initial pressure in the chamber was maintained at $1 \times 10^{-2} \mathrm{mbar}$ throughout. For deposition experiments, the RF power was typically applied for $20 \mathrm{~min}$, resulting in plasma polymer films of around $20 \mathrm{~nm}$ thickness. Substrates used were $13 \mathrm{~mm}$ coverslips, which were placed near the center of the grounded bottom plate. After deposition of plasma polymers, the substrates were stored in sealed containers prior to subsequent analysis.

A Hiden Analytical quadrupole mass spectrometer (EQP 1000) was used to measure the neutral and positively charged species in the plasma phase. The mass spectrometer was differentially pumped using a turbo molecular pump to a base pressure below $5 \times 10^{-6}$ mbar via a $300 \mu \mathrm{m}$ orifice. For residual gas analysis of the neutral mass spectrum (RGA), the influent gas was ionized using an electron impact source at $20 \mu \mathrm{A}$ and $70 \mathrm{eV}$. For positive ions, the instrument was tuned to the protonated precursor $\left(\mathrm{M}+\mathrm{H}^{+}\right)$and the ion energy distribution recorded. The instrument was then tuned to the peak intensity ion energy, and the mass spectrum acquired. Spectra were corrected for instrument transmission by assuming the peak intensity was proportional to $m^{-1}$ as advised by the manufacturer.

\section{X-ray photoelectron spectroscopy (XPS)}

A SPECS SAGE XPS system was used to obtain XP spectra with an $\mathrm{Mg} \mathrm{K} \alpha$ radiation source operating at $10 \mathrm{kV}$ and $20 \mathrm{~mA}$. The system included a Phoibos 150 hemispherical analyzer, with an MCD-9 detector. Survey spectra were recorded between 0-1000 eV at a pass energy of $100 \mathrm{eV}$ with energy steps of $0.5 \mathrm{eV}$ to determine the elements present on the surface of the plasma polymer films. High resolution spectra were then recorded for selected peaks using $0.1 \mathrm{eV}$ energy steps at a pass energy of $20 \mathrm{eV}$. All spectra were corrected for charging effects by setting the aliphatic carbon peak to $285 \mathrm{eV} .^{31}$ Processing and component fitting of the spectra were performed using CasaXPS (Neal Fairley, UK). 


\section{Fluorine derivatization of primary amines}

TFBA was used to label and quantify the primary amine concentration on the surface of the plasma polymer films using the Quantitative Elemental Analysis (QEA) method. ${ }^{32}$ Covalent coupling of TFBA to primary amines allows the surface concentration of primary amines to be determined from XPS data using the eqn (1).

$$
\frac{\left[\mathrm{NH}_{2}\right]}{[\mathrm{C}]}=\frac{[\mathrm{F}]_{\mathrm{d}}[\mathrm{N}]}{3[\mathrm{~N}]_{\mathrm{d}}[\mathrm{C}]} \times 100 \%
$$

where the subscript d refers to samples after derivatisation. Samples were taped to microscope slides $(25 \mathrm{~mm} \times 100 \mathrm{~mm})$, which were then placed in $50 \mathrm{ml}$ centrifuge tubes. $0.5 \mathrm{ml}$ of TFBA was added to the centrifuge tube, which was then sealed and placed in an oven at $45{ }^{\circ} \mathrm{C}$ for $3 \mathrm{~h}$. The samples were then removed from the centrifuge tube and analyzed by XPS.

\section{Results}

\section{XPS surface analysis}

Fig. 2 shows the XP spectra of DAP plasma polymer produced at $1 \times 10^{-2}$ mbar and $4 \mathrm{~W}$ applied RF power, which is representative of other plasma polymers produced under different conditions and with other precursors. The spectra shows characteristic peaks for $\mathrm{C} 1 \mathrm{~s}(285 \mathrm{eV})$ and N1s (399 eV) as expected for amine functionalised plasma polymers, and a small O1s $(532 \mathrm{eV})$ peak due to either residual oxygen in the chamber during plasma, or uptake of oxygen from the atmosphere post-plasma. The $\mathrm{C} 1 \mathrm{~s}$ peak consists mainly of a $\mathrm{C}-\mathrm{C} / \mathrm{H}$ peak at 285, but also exhibits asymmetry due to the incorporation of $\mathrm{C}-\mathrm{NH}_{x}$ bonds which manifests in a shoulder at around $286 \mathrm{eV}$. Uptake of oxygen post-plasma contribute $\mathrm{C}=\mathrm{O}$ and $\mathrm{N}-\mathrm{C}=\mathrm{O}$ groups which manifest at $287.9 \mathrm{eV}$ and $288.1 \mathrm{eV}$ respectively. ${ }^{33}$ Also shown are the spectra of the same plasma polymer surface after derivatization with TFBA. Successful coupling between primary amines and the TFBA is evident by the appearance of an F1s peak (690 eV) in the survey spectrum, and a small peak in the C1s at around $292.5 \mathrm{eV}$ characteristic of $\mathrm{C}-\mathrm{F}_{3}$ groups.

\section{Nitrogen to carbon ratio}

The nitrogen to carbon ratio $(\mathrm{N} / \mathrm{C})$ for plasma polymer films was determined by XPS and the results are presented in Fig. 3a. EDA showed the highest N/C at around 0.38 , followed by DAP

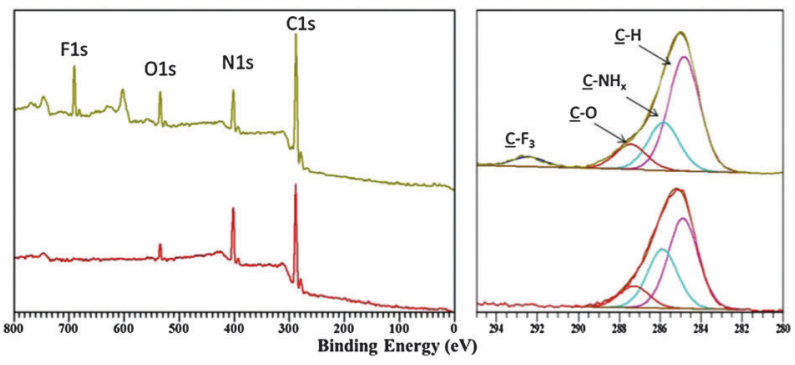

Fig. 2 Survey (left) and C1s (right) XP spectra of DAP plasma polymer deposited at $4 \mathrm{~W}$, before (bottom) and after (top) TFBA derivatization.
(0.3), AA (0.18) and HA (0.08). These values are slightly lower but similar to previous reports despite variations in operating pressure, reactor geometry etc., as shown in Table 1 . The N/C was remarkably constant with power for each precursor. The trend follows the stoichiometric N/C of each precursor, $(1,0.67$, $0.33,0.14$ respectively) but with approximately $40-60 \%$ of the nitrogen content being lost during the deposition process, again in agreement with previous studies. ${ }^{33,34}$ This is presumably due to fragmentation of the precursor in the plasma by electron impacts, and smaller fragments, such as ${ }^{\bullet} \mathrm{NH}_{2}$, being readily pumped out of the chamber.

\section{Primary amine retention}

The primary amine surface concentration, calculated from TFBA derivatization, is presented in Fig. 3b. In general, the primary amine concentration decreases with RF power for each precursor. Interestingly, the N/C data presented in Fig. 3a does not predict the primary amine concentration. EDA exhibited the highest N/C of around 0.38 , but the primary amine concentration was much lower than DAP, particularly at low power. The N/C for AA was around 2.5 times higher than HA, but the primary amine concentrations were very similar, particularly at high RF power.

\section{Neutral mass spectrometry}

Fig. 4 shows the neutral mass spectrometry of the four precursors without the plasma being ignited. The AA spectrum shows a

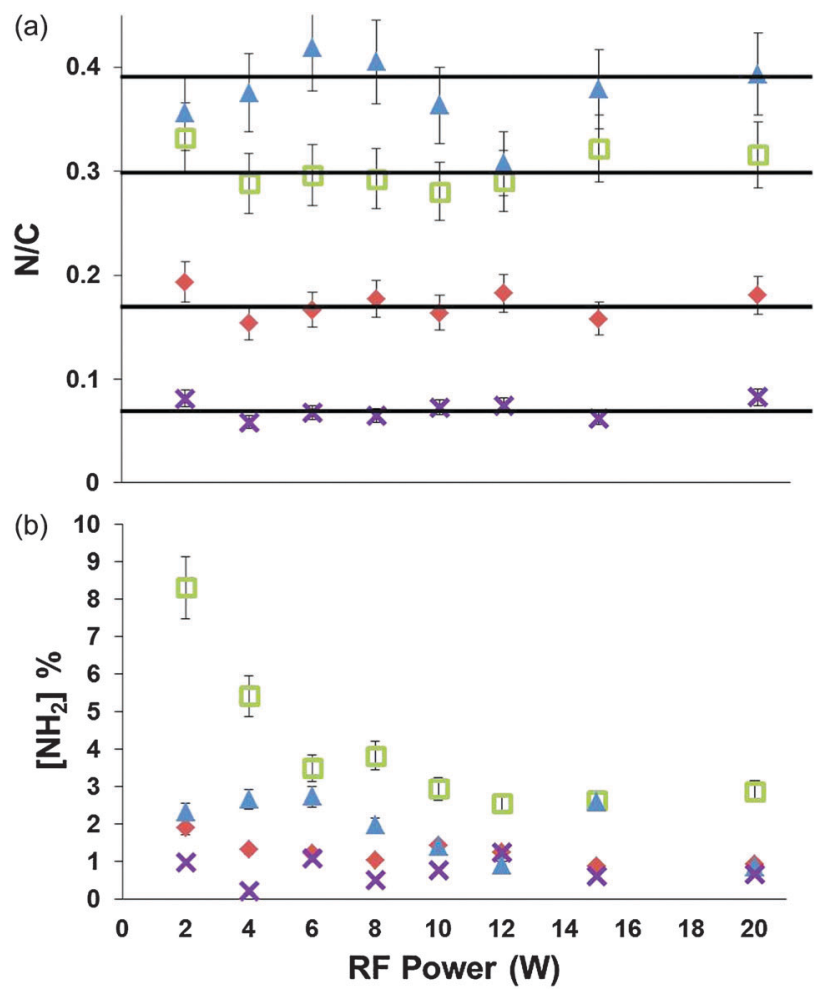

Fig. 3 (a) Nitrogen to carbon ratio for AA $(\downarrow)$, EDA $(\Delta)$, DAP $(\square)$ and HA $(\boldsymbol{X})$ as a function of RF power. (b) Primary amine group surface concentration for AA, EDA, DAP and HA as a function of RF power. Initial pressure was $1 \times 10^{-2} \mathrm{mbar}$. 
Table 1 Comparison of N/C values for each precursor with previous studies

\begin{tabular}{lll}
\hline Precursor & Average N/C & Literature value \\
\hline EDA & 0.38 & $0.37-0.82^{35}$ \\
DAP & 0.3 & $0.35-0.37^{33}$ \\
AA & 0.18 & $0.2^{36}$ \\
HA & 0.08 & $0.13^{9}$
\end{tabular}

dominant peak at $56 \mathrm{~m} / \mathrm{z}$ which corresponds to the precursor $(\mathrm{M}-\mathrm{H})^{+}$indicating the AA molecule is relatively stable under electron impacts. This may be due to the resonant double bond for allylic compounds, which for AA may exist as $\mathrm{C} 1=\mathrm{C} 2$ or $\mathrm{C} 2=\mathrm{C} 3$ and therefore strengthens the bonds in the carbon backbone of the molecule. Peaks are also evident at $30 \mathrm{~m} / \mathrm{z}$ $\left(\mathrm{CH}_{2}-\mathrm{NH}_{2}\right)$, corresponding to cleavage of the precursor at the $\mathrm{C}-\mathrm{C}$ bond as previously observed, ${ }^{25}$ and $41\left(\mathrm{CH}_{2}-\mathrm{CH}=\mathrm{CH}_{2}\right)$ and $17 \mathrm{~m} / z\left(\mathrm{NH}_{3}\right)$ corresponding to cleavage of the $\mathrm{C}-\mathrm{N}$ bond. The peak at $28 \mathrm{~m} / z$ is assigned to either $\mathrm{CH}_{2}=\mathrm{CH}_{2}{ }^{+}$or loss of two hydrogens from the $30 \mathrm{~m} / \mathrm{z}$ peak.

For EDA, DAP and HA, the precursor peaks at 60, 74 and $114 \mathrm{~m} / \mathrm{z}$ are relatively small indicating that these precursors are less stable than AA when subjected to high energy electron impacts. This has previously been explained for EDA as being due to weakening of the $\mathrm{C}-\mathrm{C}$ bond because of the proximity of two electronegative $\mathrm{NH}_{2}$ groups. ${ }^{37}$ A similar explanation can be postulated for DAP as the precursor is only one carbon longer than EDA, so weakening of the $\mathrm{C}-\mathrm{C}$ bonds would be less pronounced but still offers a plausible explanation. For both EDA and DAP, a major peak is seen at $30 \mathrm{~m} / z$, the same $\mathrm{CH}_{2}-\mathrm{NH}_{2}$ peak seen for AA. The major peak for DAP is observed at $57 \mathrm{~m} / \mathrm{z}$, corresponding to loss of $\mathrm{NH}_{2}$ from the precursor.

For HA, the precursor only has one terminal $\mathrm{NH}_{2}$ group with a 7 carbon chain backbone, so weakening of the $\mathrm{C}-\mathrm{C}$ bonds by electronegative groups is not predicted to be as important. However, the increased molecular weight gives a much higher cross-sectional area for electron impacts, resulting in increased

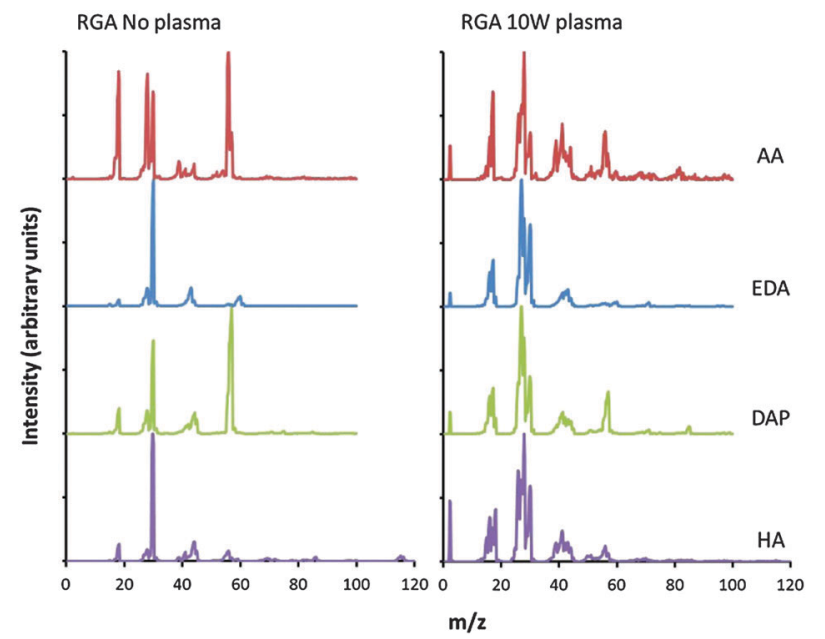

Fig. 4 Electron impact spectra of AA, EDA, DAP and HA at $1 \times 10^{-2} \mathrm{mbar}$ without plasma being ignited (left) and with plasma at $10 \mathrm{~W}$ (right). fragmentation of the precursor. Nevertheless, the peak at $30 \mathrm{~m} /$ $z$ is the dominant peak, with minor peaks at 17,44 and $57 \mathrm{~m} / \mathrm{z}$.

With the plasma ignited at $10 \mathrm{~W}$, the neutral mass spectra look remarkably similar for all four precursors as shown in Fig. 4. The major peak for all precursors occurs at 27 or $28 \mathrm{~m} / \mathrm{z}$, with smaller peaks at $17,30,41$ and $57 \mathrm{~m} / \mathrm{z}$. The peaks at 27 , $28 \mathrm{~m} / \mathrm{z}$ probably originate from $\mathrm{CH}_{2}-\mathrm{NH}_{2},(30 \mathrm{~m} / \mathrm{z})$ with subsequent loss of hydrogen atoms with further electron impacts, either in the plasma phase, or in the ionizing step in the mass spectrometer. This would result in either a diradical $\left({ }^{\bullet} \mathrm{HC}-\mathrm{NH}^{\bullet}\right),{ }^{38}$ or an unsaturated fragment where the two radicals combine to form a $\mathrm{C}=\mathrm{N}$ bond $(\mathrm{HC}=\mathrm{NH})$. Similarly, the series of peaks at $39,41,42$ and $43 \mathrm{~m} / \mathrm{z}$ may be due to loss of hydrogen from $\mathrm{CH}_{2}-\mathrm{CH}_{2}-\mathrm{NH}_{2}$. Therefore, the chemistry of the neutral species in the plasma phase appears to be quite constant for all four precursors. Scheme 1 shows examples of some reactions which occur in the plasma phase for DAP.

The neutral mass spectra for DAP were normalized, and then normalized distributions subtracted from the electron impact spectra with no plasma. These data are shown in Fig. 5, which indicates the change in mass distribution at different powers. Peaks assigned to species containing primary amines (30, 44, $57 \mathrm{~m} / \mathrm{z}$ ) decrease in relative intensity as power is increased. These species are fragmented by loss of hydrogen to $27,28,40$, 42, $56 \mathrm{~m} / \mathrm{z}$ etc. which may include hydrogen being lost from $-\mathrm{NH}_{2}$ to form $-\mathrm{NH}^{\bullet}$ or $-\mathrm{N}^{\bullet}$, all of which increase in intensity with power. Alternatively, hydrogen may be lost from the $\mathrm{CH}_{x}$ groups. The analysis in Fig. 5 shows that increasing the applied plasma power increases the likelihood of primary amines being fragmented in the plasma phase to secondary and tertiary amine radicals. Similar analysis for AA, EDA and HA shows similar trends but with even greater fragmentation of the primary amine peaks as power is increased for EDA (see ESI, $\dagger$ Fig. S1).

\section{Positive ion mass spectrometry}

The positive ion mass spectra are presented in Fig. 6. These data are normalized by the precursor molecular weight such that primary precursor and oligomeric species can be compared.

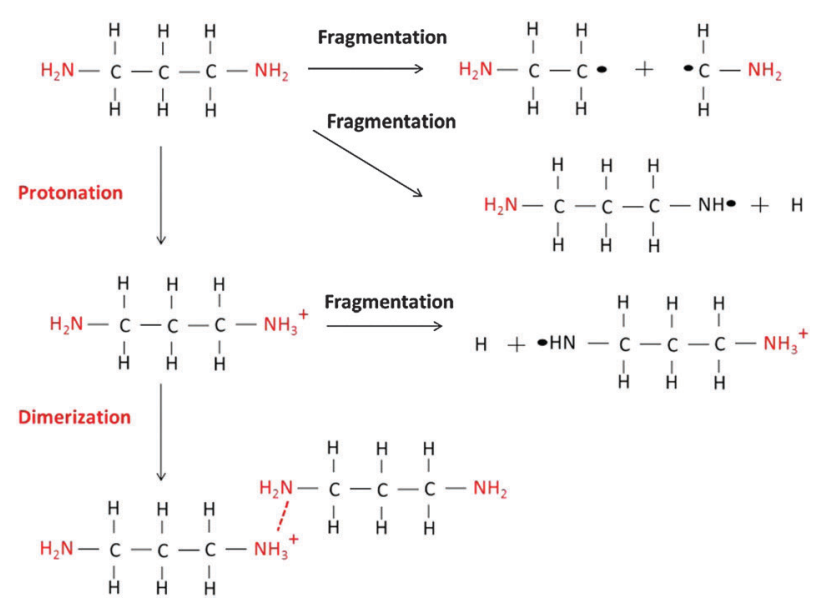

Scheme 1 Plasma phase reactions which may occur for DAP, highlighting loss and retention of primary amine groups. 


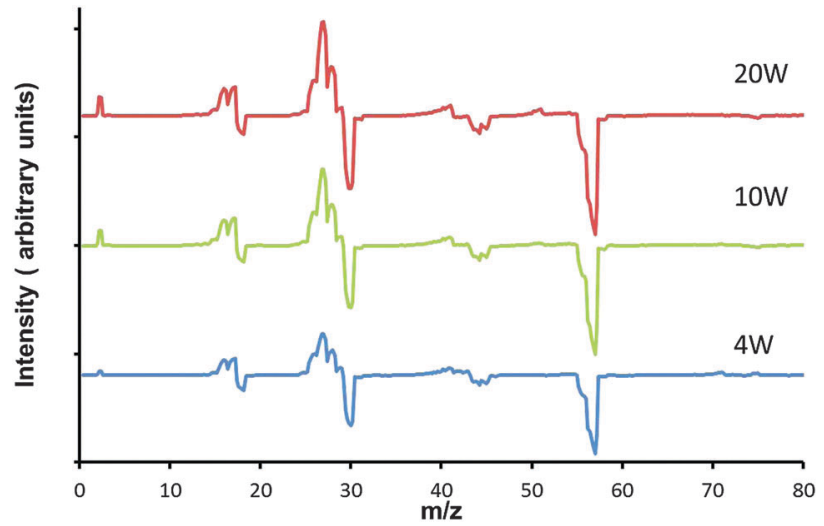

Fig. 5 Change in neutral species distribution with applied power for DAP compared to electron impact with no plasma.

At $10 \mathrm{~W}$, the dominant peak for all precursors was the protonated precursor $(\mathrm{M}+\mathrm{H})^{+}$, which is formed by proton transfer between the precursor $\mathrm{M}$, and $\mathrm{H}_{3} \mathrm{O}^{+}{ }^{39}$ Smaller fragment peaks are observed similar to the neutral mass spectra. For example, for DAP, the protonated precursor peak is seen at $75 \mathrm{~m} / z$ (see Scheme 1), with smaller fragment peaks observed at 44,30 and $17 \mathrm{~m} / \mathrm{z}$. These small fragments are particularly high in intensity for AA and HA.

Unlike the neutral mass spectra though, large, positively charged oligomeric species are observed in the plasma phase following eqn (1). ${ }^{40}$

$$
\mathrm{R}\left(\mathrm{NH}_{2}\right)_{j} \mathrm{H}^{+}+\mathrm{R}\left(\mathrm{NH}_{2}\right)_{j} \rightarrow\left[\mathrm{R}\left(\mathrm{NH}_{2}\right)_{j}\right] 2 \mathrm{H}^{+}
$$

where $j$ is either 1 (for AA and HA) or 2 (EDA or DAP). DAP shows a peak at $149 \mathrm{~m} / \mathrm{z}(2 \mathrm{M}+\mathrm{H})^{+}$, and a small peak at 223 $(3 \mathrm{M}+\mathrm{H})^{+}$. Similar oligomer peaks are observed for AA, EDA and HA. Intermediate peaks are also observed corresponding to protonated oligomers $\left(2 \mathrm{M}+\mathrm{H}^{+}\right.$and $\left.3 \mathrm{M}+\mathrm{H}^{+}\right)$after losing

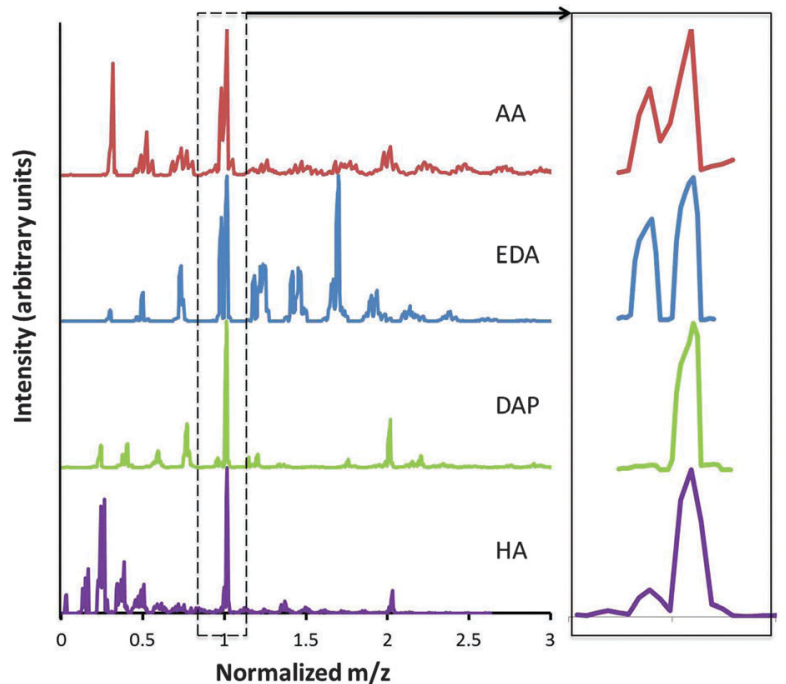

Fig. 6 Positive ion spectra of AA, EDA, DAP and HA plasmas at $10 \mathrm{~W}$ (left) and $(\mathrm{M}-\mathrm{H})^{+}$and $(\mathrm{M}+\mathrm{H})^{+}$peaks (right). Masses have been normalized by the precursor mass for comparison of intact precursor and oligomer ions. methyl and amino groups, or hydrogen. For AA, HA and in particular EDA these intermediate groups are high in intensity, similar to the neutral fragmentation pattern. DAP in contrast shows very little fragmentation of the $(2 \mathrm{M}+\mathrm{H})^{+}$oligomer. The $(\mathrm{M}+\mathrm{H})^{+}$peak for all precursors is accompanied by peaks at $(\mathrm{M}-\mathrm{H})^{+}$, assigned to the protonated precursor after loss of two hydrogens (see Fig. 6). These $(\mathrm{M}-\mathrm{H})^{+}$peaks are approximately $60 \%$ as intense as the $(\mathrm{M}+\mathrm{H})^{+}$peaks for AA and EDA, but for HA is only $13 \%$ and is even lower for DAP $(<1 \%)$. Similar to the case for the neutral species, these hydrogens may be lost from methyl groups, or from amino groups resulting in loss of primary amine functionality. DAP and HA then appear to have ionic precursor and oligomeric species which are much more stable than AA and EDA, possibly leading to increased retention of functionality. Unlike the neutral mass spectra which showed the chemistry of the plasma phase was quite similar for each precursor, the mass distribution of ionic species is quite different.

Similar to the comparative analysis of the neutral species in Fig. 5, Fig. 7 shows the change in distribution of the positive species for DAP with applied power relative to $2 \mathrm{~W}$ plasma. In the region below $\mathrm{M}+\mathrm{H}^{+}$at $75 \mathrm{~m} / \mathrm{z}$, the relative amounts of small fragments increased with power, as expected due to increased electron density in the plasma and greater likelihood of fragmentation due to electron impacts. The relative amount of dimer $(2 \mathrm{M}+\mathrm{H})^{+}$increased with power. This can be explained by an increase in the amount of reactive species in the plasma phase as the plasma density increases. This increases the likelihood of ionized precursor molecules colliding and forming dimers. Of particular interest is the decrease in the relative amounts of species between $\mathrm{M}+\mathrm{H}^{+}$and $2 \mathrm{M}+\mathrm{H}^{+}$. The peaks at $131,117,103$ and $89 \mathrm{~m} / z$ correspond to $2 \mathrm{M}+\mathrm{H}^{+}$after the loss of $\mathrm{NH}_{2}$, and then subsequent $\mathrm{CH}_{2}$ groups.

\section{Stability}

Plasma polymer films at each condition were prepared such that their thicknesses were $\sim 20 \mathrm{~nm}$. To assess the stability of these films, they were placed in Milli-Q water for 1 hour without agitation, then rinsed briefly before being dried under dry nitrogen.

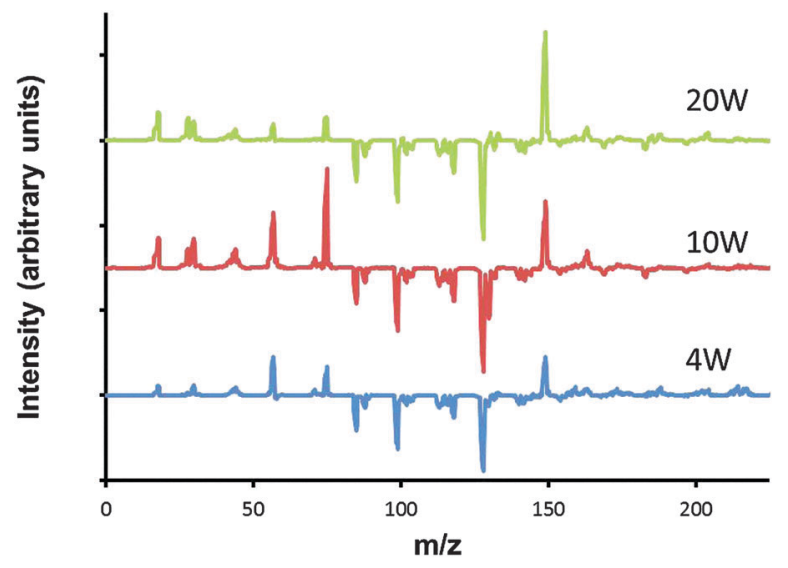

Fig. 7 Change in positive ion distribution with applied power for DAP compared to $2 \mathrm{~W}$ plasma. 
The samples were then analysed by XPS. Fig. 8 shows the silicon signal as detected by XPS as a function of initial primary amine content. The presence of silicon in the spectra indicates the dissolution of the film, as the depth of analysis for XPS is of the order of $5-10 \mathrm{~nm} .^{41}$ The results show that HA and AA are very stable, with only minor amounts of silicon present when the primary amine content was high (i.e. at low power). EDA showed a significant increase in the silicon signal, particularly at high primary amine concentrations. This is consistent with previous measurements using the current reactor, although at a higher pressure ${ }^{25}$ which showed that EDA films were unstable except at high power. Indeed, from the data it is likely that the EDA films at low power were almost completely dissolved. Interestingly, DAP also exhibited silicon peaks at high primary amine content, but the EDA and DAP plots do not overlap; the dissolution of DAP films occurs at much higher primary amine concentrations that EDA. DAP plasma polymers with $3 \%$ primary amine content were still stable, while EDA plasma polymers with the same primary amine content were almost completely dissolved.

Also shown is the change in nitrogen concentration after contact with water. HA and AA decreased in nitrogen only slightly, with DAP showing a slightly higher decrease. Plasma polymers at lower power decreased in nitrogen more than higher power. This is consistent with the primary amine content, as it has been shown that primary amines provide sites for water to hydrogen bond and thus dissolve short attached hydrocarbon chains. ${ }^{42,43}$ EDA showed the largest decrease in nitrogen content, particularly at low power, despite the fact that DAP had a higher
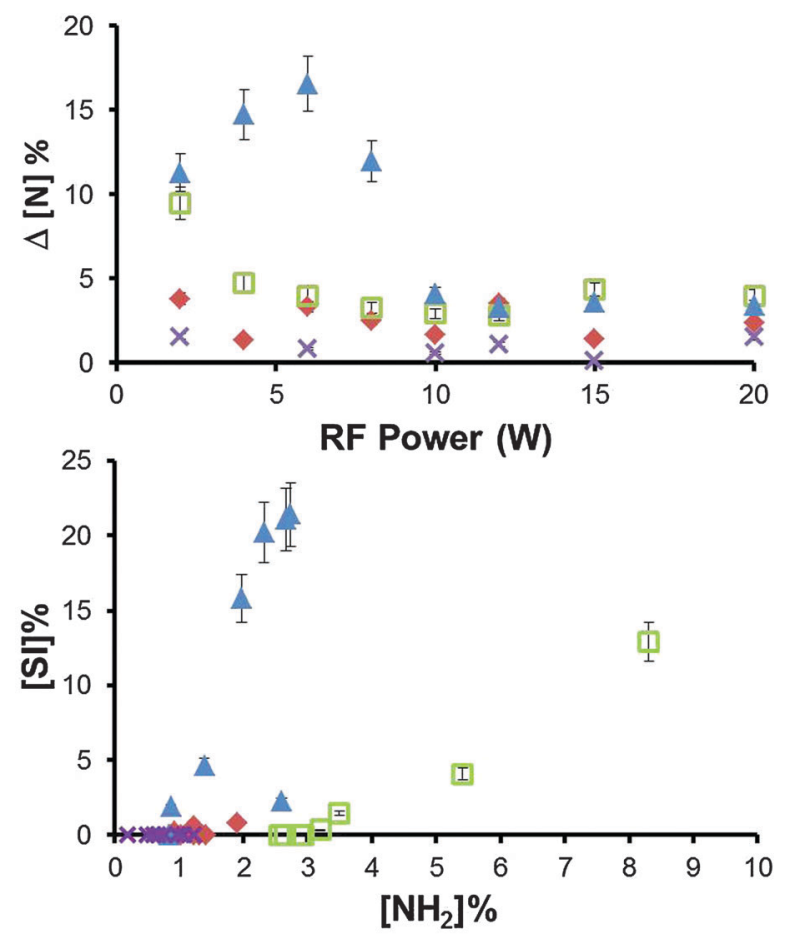

Fig. 8 Stability of AA ( $)$, EDA ( $\boldsymbol{\Delta})$, DAP $(\square)$ and HA ( $\boldsymbol{X}$ ) plasma polymers as shown by change in nitrogen content (top) and appearance of the substrate silicon peak (bottom) after washing in Milli-Q water for 1 hour. primary amine content (see Fig. 3). The lower than expected decrease in nitrogen at $2 \mathrm{~W}$ and $4 \mathrm{~W}$ for EDA is probably due to the plasma polymer being almost completely dissolved, leaving a very thin layer in intimate contact with the substrate. It has been shown previously that the chemistry of amines ${ }^{44}$ and other plasma polymers ${ }^{45}$ close to substrates is different to that in the bulk of the film.

\section{Discussion}

Retention of functionality in plasma polymerisation is dependent on two processes; fragmentation/oligomerisation in the plasma phase due to electron impacts, and deposition and sputtering processes at the surface.

\section{Plasma phase}

Electrons heated by the applied electric fields in the plasma typically have a Druyvesteyn distribution of temperatures. ${ }^{46}$ Average electron temperatures of $3 \mathrm{eV}$ are typical, but a small proportion may have temperatures greater than $10 \mathrm{eV}$. Electrons impacting molecules with energies of $3-5 \mathrm{eV}$ can result in fragmentation due to dissociation reactions, giving rise to radical species. $\mathrm{C}-\mathrm{H}$ and $\mathrm{N}-\mathrm{H}$ bonds are relatively strong (typically $\sim 100-110 \mathrm{kcal} \mathrm{mol}^{-1}$ ) while $\mathrm{C}-\mathrm{C}$ and $\mathrm{C}-\mathrm{N}$ bonds are slightly weaker $\left(\sim 85-90 \mathrm{kcal} \mathrm{mol}^{-1}\right) .{ }^{37}$ Thus, in the case of a single electron impact with an organic molecule containing amine groups, the most likely bonds to be broken would be the $\mathrm{C}-\mathrm{C}$ and $\mathrm{C}-\mathrm{N}$ bonds. This is shown in Fig. 4 for the RGA with no plasma data which gives rise to ${ }^{\bullet} \mathrm{NH}_{2},{ }^{\bullet} \mathrm{CH}_{2}-\mathrm{NH}_{2}$, and - $\mathrm{CH}_{2}-\mathrm{CH}_{2}-\mathrm{NH}_{2}$ species. As the applied RF power is increased, the plasma and electron density increases which increases the probability of molecules undergoing multiple electron impacts. Therefore it is more likely that $\mathrm{C}-\mathrm{H}$ and $\mathrm{N}-\mathrm{H}$ bonds may be broken as shown in Fig. 5 where the relative intensity of primary amine containing groups are decreased. Thus retention of primary amine groups in radical species is high at low applied RF power, but increasing the RF power leads to increased probability of primary amines losing hydrogen and being converted into secondary and tertiary amines.

Higher energy electron impacts $(>10 \mathrm{eV})$ result in ionization of neutrals. For all precursors, at low power the dominant ionic species is the protonated monomer, retaining the primary amine functionality. However loss of hydrogen also occurs, which may be due to release of excess energy from the ionizing electron impact, or secondary electron impacts. For the $\mathrm{M}+\mathrm{H}^{+}$ion, loss of hydrogen occurs most readily for EDA and AA, while precursor ions of HA and DAP are more stable. While the chemistry of the neutral species are dominated by fragmentation reactions, ionic oligomeric species are formed in the plasma phase, vastly increasing the complexity of the ion chemistry. There is competition between oligomerisation and fragmentation reactions, as shown by the formation of the $2 \mathrm{M}+\mathrm{H}^{+}$ion, but then fragmentation of this oligomer to smaller species, for example $2 \mathrm{M}-\mathrm{NH}_{2}{ }^{+}$. EDA in particular shows fragmentation of dimer oligomers. 
Therefore, from the plasma phase analysis, DAP appears to favour structures which retain primary amine functionality, while in contrast EDA exhibits noticeably more loss of hydrogen which can contribute to loss of primary amines.

\section{Surface interactions}

In the initial stages of deposition, the surface is activated by high energy ion impacts which cause scission of the bonds at the surface of the substrate. The radical sites which result can then enable plasma phase species to deposit, forming a covalent bond between the depositing molecule and the surface (see Scheme 2). After this initial stage, plasma polymers grow via three main mechanisms; direct ionic deposition, radical termination and radical propagation. ${ }^{47}$ Radical propagation can only occur via carbon-carbon double bonds, which are not present in EDA, DAP and HA. Therefore EDA, DAP and HA deposition must be dominated by ionic deposition and radical termination reactions. AA contains an allylic bond, which in traditional polymerisation have been shown to polymerize slowly and have increased probability of terminating. ${ }^{48}$ It has been shown that plasma deposition of allylic precursors is dominated by ionic processes. ${ }^{49}$ It is possible for species containing double bonds to be created in the plasma through formation of diradicals, however the fraction of such species would be extremely low. Thus, radical propagation reactions can largely be discounted as a growth mechanism for the precursors studied here.

Due to the sheath voltages which are created by the plasma, at low pressure ions are accelerated to surfaces and arrive at energies of a few tens of $\mathrm{eV}$ and this increases with power due to an increase in electron temperature. ${ }^{50}$ These ion impacts can result in ion deposition (see below) or creation of radical sites. The resulting radical sites are then available for radical termination reactions with plasma phase radical species. Unlike ions, radicals are not accelerated to the surface due to sheath voltages, and so arrive at the surface by diffusion at approximately ambient temperature. Radicals then utilize chemical free energy gained in the plasma phase, rather than kinetic energy to drive deposition. Thus if radical processes were the only mechanism by which plasma polymers could grow, the process of radical termination reactions result in retention of functionality, and the limiting factor is retention in the plasma phase.

However, ions are also important in plasma polymerisation. While radical species utilize chemical free energy to adsorb to the plasma polymer surface, ions must utilize kinetic energy to overcome any energetic barrier to deposition. Ionic adsorption has been shown to be important in the deposition of AA. ${ }^{51}$ This is in part due to the fact that $\mathrm{AA}$ is a stable precursor, as it exhibits low fragmentation into radical species in the plasma phase compared to other precursors studied here, as shown in Fig. 4. The sticking probability of ionic species is dependent on the energy with which the ions impact the surface. Increasing the ion energy increases the sticking probability of the ion, ${ }^{52}$ but also increasing ion energy above $\sim 15 \mathrm{eV}$ increases the rate of ablation and damage to the existing surface. ${ }^{53}$ Plasma polymers are typically deficient in hydrogen due to abstraction of hydrogen ${ }^{26,54}$

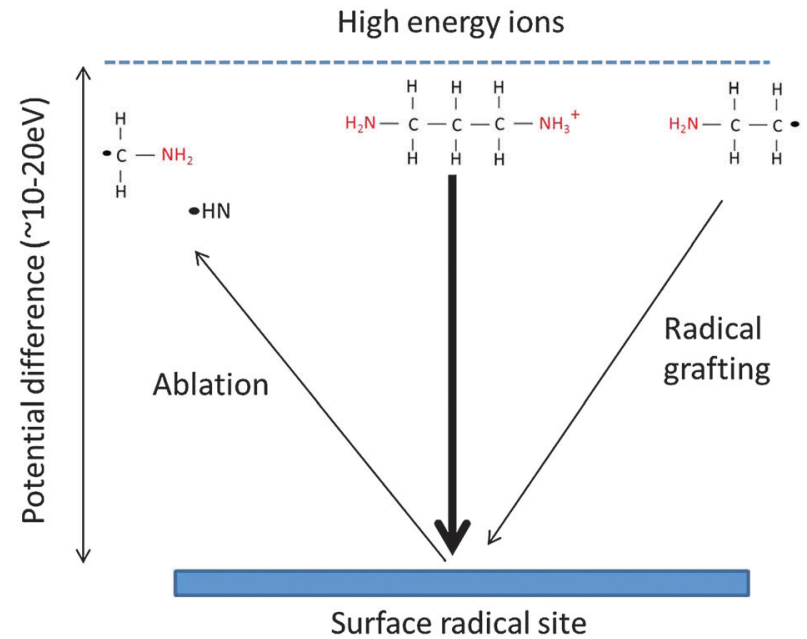

Scheme 2 Surface interactions of high energy ions, creating radical sites, enabling radical grafting.

and it is likely that some of the lost hydrogen will be from surface amine groups. Thus, retention of ionic functional amine groups in the plasma phase may not lead to retention in the deposited thin film, as they may be fragmented/rearranged after subsequent ion impacts on the surface. In fact, ions which do not deposit on the surface may still reduce functional group retention by abstracting hydrogen from radicals and ions already deposited. The ion energy for the plasmas used in this study varied from $\sim 10 \mathrm{eV}$ at $2 \mathrm{~W}$ up to $\sim 28 \mathrm{eV}$ at $20 \mathrm{~W}$. Thus, at low power, while the sticking probability of the ions is expected to be low, loss of functionality due to surface bombardment should be minimized. However, at higher power we can expect a high degree of fragmentation/rearrangement on the surface, and thus loss of primary amine groups.

\section{Stability}

Stability in aqueous media of amine functionalised plasma polymers is determined by primary amine density and the degree of cross-linking of the plasma polymer. Cross-linking increases the average molecular weight of the polymer chain attached to each amine group ${ }^{25}$ which decreases solubility. In addition to losing amine functionality, ion bombardment increases the cross-link density for plasma polymers. ${ }^{55} \mathrm{AA}$ and HA plasma polymers are low in primary amines (maximum $\sim 2 \%$ ) and thus are quite insoluble in aqueous solution, with only a small loss of nitrogen from the surface. In contrast, EDA and DAP plasma polymers exhibit solubility at high primary amine concentrations, but their behaviours are quite different. EDA plasma polymers with only $\sim 1 \%$ primary amine concentration exhibit some solubility, and at $2 \%$ are almost completely soluble. DAP plasma polymers on the other hand are stable up to $\sim 3 \%$ primary amine. The difference in solubility between EDA and DAP plasma polymers with the same primary amine density may be related to the relative densities of secondary amines (which are still soluble, but less so than primary amines) or an increase in crosslinking of the plasma polymers. Hegemann et al. describe the effect 
of momentum transfer from high energy ions to the surface in the densification of plasma polymers. ${ }^{56}$ For ions of different masses which traverse the plasma sheath, while the kinetic energy delivered to the surface is constant, the momentum transfer is proportional to $m^{1 / 2}$. The average ion masses for EDA and DAP at $10 \mathrm{~W}$ are 83.9 and 96.0 amu respectively. Thus, with larger ions for DAP, the momentum transfer to the growing DAP plasma polymer would be higher, resulting in a higher degree of cross linking.

\section{Conclusions}

Plasma phase mass spectrometry is a powerful tool for measuring reactions in the plasma phase, and the species which impact surfaces in plasma polymerisation. For the four precursors studied here, nitrogen to carbon ratio is not a good predictor of surface functionality. This is due to the ease with which some precursors (EDA in particular) fragment with electron impacts in the plasma losing primary amine groups, while others (e.g. DAP) favour structures which retain primary amines.

While plasma phase reactions are important, plasma-surface interactions can also be the cause of loss of functionality due to sputtering, and certainly affect the degree of cross-linking in the surface. These factors combined determine the functional group density and solubility of aminated plasma polymers, and thus their practicality. Increased understanding of the processes in the plasma phase and at the surface are therefore critical in intelligently designing improved plasma polymerisation processes.

\section{References}

1 P. Roach, T. Parker, N. Gadegaard and M. R. Alexander, Surf. Sci. Rep., 2010, 65, 145-173.

2 M. Ohring, The Materials Science of Thin Films, Academic Press, Hoboken, New Jersey, 1992.

3 S. Prakash, M. B. Karacor and S. Banerjee, Surf. Sci. Rep., 2009, 64, 233-254.

4 F. Variola, F. Vetrone, L. Richert, P. Jedrzejowski, J.-H. Yi, S. Zalzal, S. Clair, A. Sarkissian, D. F. Perepichka, J. D. Wuest, F. Rosei and A. Nanci, Small, 2009, 5, 996-1006.

5 K. S. Siow, L. Britcher, S. Kumar and H. J. Griesser, Plasma Processes Polym., 2006, 3, 392.

6 T. Michl, B. R. Coad, M. Doran, M. Osiecki, M. H. Kafshgari, N. H. Voelcker, A. Husler, K. Vasilev and H. J. Griesser, Chem. Commun., 2015, 51, 7058-7060.

7 S. Bouaidat, C. Berendsen, P. Thomas, S. G. Petersen, A. Wolff and J. Jonsmann, Lab Chip, 2004, 4, 632-637.

8 B. R. Coad, K. E. Styan and L. Meagher, ACS Appl. Mater. Interfaces, 2014, 6, 7782-7789.

9 K. Vasilev, N. Poulter, P. Martinek and H. J. Griesser, ACS Appl. Mater. Interfaces, 2011, 3, 4831-4836.

10 F. S. H. Krismastuti, H. Bayat, N. H. Voelcker and H. Schönherr, Anal. Chem., 2015, 87, 3856-3863.

11 Z. Jiang and Z. Jiang, J. Membr. Sci., 2014, 456, 85-106.
12 N. G. Walker, A. Mistry, L. E. Smith, P. C. Eves, S. Forster, G. Tsaknakis, S. Watt and S. MacNeil, Tissue Eng., Part C, 2012, 18, 143-1552.

13 G. Kirby, L. Vandenpoel, J. Pinxteren, R. Short and A. Michelmore, Cytotherapy, 2015, 17, S14.

14 A. Hucknall, S. Rangarajan and A. Chilkoti, Adv. Mater., 2009, 21, 2441-2446.

15 B. Dong, H. Jiang, S. Manolache, A. C. Lee Wong and F. S. Denes, Langmuir, 2007, 23, 7306-7313.

16 C. D. Heyes, J. Groll, M. Moller and G. U. Nienhaus, Mol. BioSyst., 2007, 3, 419-430.

17 P. Wang, K. L. Tan, E. T. Kang and K. G. Neoh, J. Mater. Chem., 2001, 11, 2951-2957.

18 J. Goodman, J. Polym. Sci., 1960, 44, 551-552.

19 H. K. Yasuda, Plasma Polymerisation, Academic Press, London, U.K., 1985.

20 M. Miyama, Y. Yang, T. Yasuda, T. Okuno and H. K. Yasuda, Langmuir, 1997, 13, 5494-5503.

21 A. Michelmore, D. A. Steele, D. E. Robinson, J. D. Whittle and R. D. Short, Soft Matter, 2013, 9, 6167-6175.

22 B. Chapman, Glow Discharge Processes, John Wiley and Sons, Chichester UK, 1980.

23 S. Ligot, M. Guillaume, P. Gerbaux, D. Thiry, F. Renaux, J. Cornil, P. Dubois and R. Snyders, J. Phys. Chem. B, 2014, 118, 4201-4211.

24 L. Denis, D. Cossement, T. Godfroid, F. Renaux, C. Bittencourt, R. Snyders and M. Hecq, Plasma Processes Polym., 2009, 6, 199-208.

25 C. Daunton, L. E. Smith, J. D. Whittle, R. D. Short, D. A. Steele and A. Michelmore, Plasma Processes Polym., 2015, 12, 817-826.

26 S. Peter, K. Graupner, D. Grambole and F. Richter, J. Appl. Phys., 2007, 102, 0533304.

27 J. Trieschmann and D. Hegemann, J. Phys. D: Appl. Phys., 2011, 44, 475201.

28 L. O'Toole, A. J. Beck, A. P. Ameen, F. R. Jones and R. D. Short, J. Chem. Soc., Faraday Trans., 1995, 91, 3907-3912.

29 P. Hamerli, T. Weigel, T. Groth and D. Paul, Biomaterials, 2003, 24, 3989-3999.

30 A. Michelmore, J. D. Whittle, R. D. Short, R. W. Boswell and C. Charles, Plasma Processes Polym., 2014, 11, 833-841.

31 G. Beamson and D. Briggs, High Resolution XPS of Organic Polymers: The Scienta ESCA300 Database, John Wiley and Sons, Chichester, U.K., 1992.

32 J. C. Ruiz, S. Taheri, A. Michelmore, D. E. Robinson, R. D. Short, K. Vasilev and R. Forch, Plasma Processes Polym., 2014, 11, 888-896.

33 T. R. Gengenbach and H. J. Griesser, J. Polym. Sci., Part A: Polym. Chem., 1999, 37, 2191-2206.

34 C.-G. Golander, M. W. Rutland, D. L. Cho, A. Johansson, H. Ringblom, S. Jonsson and H. K. Yasuda, J. Appl. Polym. Sci., 1993, 49, 39-51.

35 H. Biederman, I. H. Boyaci, P. Bilkova, D. Slavinska, S. Mutlu, J. Zemek, M. Trchova, J. Klimovic and M. Mutlu, J. Appl. Polym. Sci., 2001, 81, 1341-1352.

36 D. E. Robinson, A. Marson, R. D. Short, D. J. Buttle, A. J. Day, K. L. Parry, M. Wiles, P. Highfield, A. Mistry and J. D. Whittle, Adv. Mater., 2008, 20, 1166-1169. 
37 S. J. Blanksby and G. B. Ellison, Acc. Chem. Res., 2003, 36, 255-263.

38 S. Pedersen, J. L. Harek and A. H. Zewail, Science, 1994, 266, 1359-1364.

39 A. Michelmore, D. A. Steele, J. D. Whittle, J. W. Bradley and R. D. Short, RSC Adv., 2013, 3, 13540-13557.

40 H. Wincel and J. A. Herman, J. Chem. Soc., Faraday Trans., 1973, 69, 1797-1810.

41 D. Briggs, Surface analysis of polymers by XPS and static SIMS, Cambridge University Press, Cambridge, 1998.

42 A. O. Christie and D. J. Crisp, J. Appl. Chem., 1967, 17, 11-14.

43 R. M. Stephenson, J. Chem. Eng. Data, 1993, 38, 625-629.

44 K. Vasilev, A. Michelmore, H. J. Griesser and R. D. Short, Chem. Commun., 2009, 3600-3602.

45 R. T. Chen, B. W. Muir, L. Thomsen, A. Tadich, B. C. C. Cowie, G. K. Such, A. Postma, K. M. McLean and F. Caruso, J. Phys. Chem. B, 2011, 115, 6495.

46 M. J. Druyvesteyn and F. M. Penning, Rev. Mod. Phys., 1940, 12, 87-174.

47 G. Padron-Wells, B. C. Jarvis, A. K. Jindal and M. J. Goeckner, Colloids Surf., B, 2009, 68, 163-170.
48 P. J. Flory, Principles of Polymer Chemistry, Cornell University Press, New York, 1953.

49 A. Michelmore, C. Charles, R. W. Boswell, R. D. Short and J. D. Whittle, ACS Appl. Mater. Interfaces, 2013, 5, 5387-5391.

50 M. A. Lieberman and A. J. Lichtenberg, Principles of Plasma Discharges and Materials Processing, John Wiley and Sons, Hoboken, NJ, 2005.

51 A. Choukourov, H. Biederman, D. Slavinska, L. Hanley, A. Grinevich, H. Boldryeva and A. Mackova, J. Phys. Chem. $B, 2005$, 109, 23086-23095.

52 P. N. Brookes, S. Fraser, R. D. Short, L. Hanley, E. Fuoco, A. Roberts and S. Hutton, J. Electron Spectrosc. Relat. Phenom., 2001, 121, 281-297.

53 D. C. Jacobs, Annu. Rev. Phys. Chem., 2002, 53, 379-407.

54 A. Nelson, B. W. Muir, J. Oldham, C. Fong, K. M. McLean, P. G. Hartley, S. K. Oiseth and M. James, Langmuir, 2006, 22, 453-458. 55 A. Choukourov, I. Gordeev, D. Arzhakov, A. Artemenko, J. Kousal, O. Kylián, D. Slavínská and H. Biederman, Plasma Processes Polym., 2012, 9, 48-58.

56 D. Hegemann, E. Korner, N. Blanchard, M. Drabik and S. Guimond, Appl. Phys. Lett., 2012, 101, 211603. 